\title{
Building up Reflective Communities through Exploring the Perception of Adult Educators' in Actual Practise
}

\author{
Dr. Bengi Sonyel \\ Eastern Mediterranean University \\ Faculty of Eduactional Sciences \\ Department of Education, Cyprus
}

\section{Doi:10.5901/jesr.2013.v3n7p218}

\begin{abstract}
This research paper intends to unravel the perception of adult educators on reflective practice; whether there is a disparity between belief and actual practice, and factors that affect their involvement in reflective practice. The purpose of the present study is three-pronged: (1) to have a better understanding of the various viewpoints on reflective practice held by adult educators; (2) to enhance my research competence through reflecting upon research practice; and (3) to foster reflective practice through forming a collaborative research community. This research paper is basically divided into three parts. The first part (Chapter 2) provides a review of the conceptual framework of reflective practice through a critical examination of the divergent viewpoints raised by various researchers and practitioners. Although it is hard to bring together the divergent viewpoints into a coherent framework, the review attempts to set the theoretical orientation to the research study. The second part (Chapter 3) is on the research study. Four research questions have been set to guide the research study. This chapter will discuss the instrument used for data collection and synthesis the findings of the research study. The third part (Chapter 4) is a summary of the insights that the researcher gained from the research study as a reflective practitioner. This chapter also highlights the merits of a collaborative research community.
\end{abstract}

Keywords: Reflective practise; collaborative research; and adult education.

\section{Introduction}

This research paper intends to unravel the perception of adult educators on reflective practice; whether there is a disparity between belief and actual practice, and factors that affect their involvement in reflective practice. The purpose of the present study is three-pronged: (1) to have a better understanding of the various viewpoints on reflective practice held by adult educators; (2) to enhance my research competence through reflecting upon research practice; and (3) to foster reflective practice through forming a collaborative research community.

\section{The Inception of Reflective Practice in Continuing Professional Development of Teachers}

In the early 1970s Argyris and Schon (1974) developed the notion of single loop and double loop learning, and emphasised the need to move from the former, in which pedagogic efforts remain at the private level, to the latter, in which thinking and practice are raised to an explicit, publicly accessible level, so as to empower growth. Since then, the nature and practice of reflection has been the subject of discussion and research, particularly by those researcherpractitioners engaged in the action research movement (Day, 1993).

Since the early 1980s there has been a great deal of discussion about educating reflective practitioners particularly in professions such as teaching, nursing and social work where field experience and academic course work need to be closely integrated (Schon 1987; Zeichner and Liston 1987; Korthagen 1988; Clift, Houston and Prignach 1990; Smith and Hatton 1993; Palmers, Burns and Bulman 1994, cited in Gould and Taylor, 1996). Such discussion has pointed out the importance of focusing on the artistry of practice and, within courses, of creating opportunities for students to engage in activities which promote reflective practice (Boud and Knights, 1996).

The concept of reflection is not a novelty in education, but the terms 'reflection' and 'reflective practice', according to Cole (1997), have gained their popularity only in the last two decades. In the late 1970s and early 1980s, in response to the movement to reconceptualise teacher knowledge and the call for the professionalisation of teaching and teacher education (Korthagen, 1993), the teacher education community started to address the notions of reflection through the 
works of a great number of scholars. Since then the concept has been explored in greater depth and translated into diverse theoretical frameworks, which gradually develop into a guiding principle for teacher education.

\title{
2.1 Why Reflection/Reflective Practice
}

\subsubsection{As a means for professional development}

McLaughlin (1993) maintains that capacity for reflection, feedback, and problem solving were of central importance to communities of professionals endeavouring to respond effectively to today's students, and classroom challenges beyond the capacity of an individual teacher result in collective reflection and development. He puts it:

\begin{abstract}
'Effective responses to the challenges of contemporary classrooms require a spirited, reflective professional community of teachers - a workplace setting that allows examination of assumptions about practice, focuses collective expertise on solutions based on classroom realities, and support efforts to change and grow professionally.' (McLaughlin 1993: 98)
\end{abstract}

\subsubsection{As a bridge between theory and practice}

The existing experience of practitioners is an important source of knowledge, and the ability to reflect on and share experience is a powerful form of learning. It is maintained that the use of reflective practice both assists in the integration of theory with practice and enables practitioners to improve their skills of clinical reasoning (Williams 1998). In fact it is argued that professionals can be assisted to formulating theories from their practice at different levels of reflection (Griffiths \& Tann 1992).

Williams (1998) notes that professionals need to retain critical control over the more intuitive aspects of their practice by regular reflection, self-evaluation and the opportunity to learn from colleagues. By these means, practice does not remain at a standstill, but is open to challenge and review. Therefore, in creating a learning environment in which reflective practice is encouraged, the gap between theory and practice can be explored and new theories developed.

\subsubsection{As an aim of education}

Van Manen (1995) stresses that teaching is not only governed by principles of effectiveness, but also by special normative, ethical, or affective considerations. As such, reflective thinking is important not only as a tool for teaching, but also as an aim of education, said Dewey (1964: 211), since "it enables us to know what we are about when we act. It converts action that is merely appetitive, blind, and impulsive into intelligent action".

\subsubsection{As an integral part of professional practice}

The concept of the teacher as a reflective practitioner is, in part, a response to the sense that a technical theory-intopractice epistemology does not seem sensitive to the realisation that teacher knowledge must play an active and dynamic role in the ever-changing challenges of the school and classroom maintains that capacity. Fox presses a similar view as that of Van Manen (1995). He maintains that classroom teaching roles and the intellectual and emotional demands placed upon teachers will become more complex as the expectations of society and the needs of learners change. Engaging routinely in reflection upon thinking and practice is, therefore, a necessity in order to sustain professional health and competence. Day (1999b: 1) further notes that "it is generally agreed that reflection in, on and about practice is essential to building, maintaining and further developing the capacities of teachers to think and act professionally over the span of their careers."

Likewise, Carr and Kemmis argue that,

"... the ideas that guide action are just as subject to change as the action itself. Therefore, only through a fundamental shift in our beliefs, values and feeling about teaching and learning, will we be effective in bringing about significant change in our practice. Creating a culture of critical reflection enhances our educative potential, and provides practitioners with opportunities to deconstruct conventional ... practices."

Carr and Kemmis (1986: 33) 


\title{
2.2 The Underpinning Conceptual Basis of Reflection / Reflective Practice / Reflective Practitioners / Reflective Process
}

\subsubsection{Definitions of Reflection/Reflective Practice/Reflective Practitioner}

After sifting through the mound of existing literature on reflection/reflective practice/reflective practitioner, I found that the literature contained quite different interpretations to the concepts. In my view, it is largely due to the evolving theoretical and practical possibilities associated with the notions that have been engendered over the years.

Within the context of recent research on teacher thinking and practice much attention has been focused on the concept of reflection. Reflection as a term is used in a number of different ways by different authors. The concept of reflection is challenging and may refer to a complex array of cognitively and philosophically distinct methods and attitudes (van Manen, 1995). A number of definitions have been contributed by various researchers and practitioners, and they are highlighted as follows:

\subsubsection{On 'reflection'}

Reflection can be used as a generic term for those intellectual and affective activities in which individuals engage to explore their experiences in order to lead to new understandings and appreciations (Boud, Keogh and Walker, 1985). A more sophisticated definition of the notion is offered by Eraut:

\begin{abstract}
"... a process in which practitioners think about their experiences after the event in order to consider what had happened and why, and whether something different might have helped. The reflective process does not attempt to deroutinise, to make everything rational or to challenge every assumption; but it does enable [a practitioner] to work at their practice, modify it and keep it under critical control. At a more sophisticated level it shades into some kind of action research." (Eraut, 1989: 175)
\end{abstract}

\subsubsection{On 'reflective practice'}

\begin{abstract}
"Reflective practice is a particularly intimate mode of research aimed at improving practice through systematic critical enquiry. The use of the term 'critical' implies review leading to a better understanding of practice and offering potential emancipation from existing traditions or established patterns of practice." (Carr and Kemmis 1986)
\end{abstract}

"In the real world reflective practice should be seen as a process whereby problems are identified and situations ameliorated through a process of pragmatic reformulation." (Golby \& Appleby, 1995: 158)

\subsubsection{On 'reflective practitioners'}

Reflective practitioners are those who are able to investigate their teaching and to think critically about their work (Doyle 1990). Fenstermacher (1986)states that being able to establish reasons for one's action and to act in accordance with one's reasons is essential to autonomous professional teaching. Thus, the essence of reflection is the interaction of experiences with analysis of beliefs about those experiences (Newell 1996).

Copeland et al (1991) promote reflective practice as a 'process of solving problems and reconstructing meaning', and they develop four assumptions underpinning their operational definitions of reflective teachers. They are as follows:

1. Engaging in reflective practice involves a process of solving problems and reconstructing meaning;

2. Reflective practice in teaching is manifested as a stance towards inquiry;

3. The demonstration of reflective practice is seen to exist along a continuum or 'reflective spectrum'; and

4. Reflective practice occurs within a social context.

Although there are many different conceptualisations of reflection and reflective teaching, most of them seem to share the underlying assumption that teachers should use logical, rational, step-by-step analyses of their own teaching and the contexts in which that teaching takes place. Language, whether spoken or written, plays a central role in these analyses (Korthagen (1993).

\subsubsection{The Essence of Reflective Practice}

Ghaye and Ghaye (1999) bring forward ten principles that convey the essence of reflective practice as follows:

1. needs to be understood as a discourse; 
2. reflective practice is fuelled and energised by experience;

3. is a process that involves a reflective turn;

4. is concerned with learning how to account for ourselves;

5. should be understood as a disposition to inquiry; and

6. is interest-serving, when we reflect we are engaging in a process of knowledge creation;

7. is enacted by those who are critical thinkers;

8 . is a way of decoding a symbolic landscape;

9. sits at the interface between notions of practice and theory; and

10. is a postmodernist way of knowing.

They go on to say that becoming a teacher and continuing our professional development thereafter is a challenging and complex business. Central to this process is our ability to reflect constructively and critically on our teaching intentions, the ends we have in mind and the means we might use to achieve them. At the heart of this process is the reflective conversation, a medium through which we are able to learn from our teaching experiences and question the educational values that give a shape, form and purpose to our practice.

\subsubsection{Reflection Process}

Boud, Knights and Walker (1985) developed a three-stage model of the reflection process: returning to the experience, attending to feelings connected with the experience and re-evaluating the experience through recognizing implications and outcomes. This model is subsequently been extended into a model for facilitating learning from experience (Boud and Walker 1990; Boud 1993). The essence of this model is that learning from experience can be enhanced through both reflection-in-action, that is reflection which occurs in the midst of experience, and through reflection-on-action, that is reflection after an event. The model illustrates that reflection is grounded in the personal foundation of experience of the learner. Learning occurs through the interaction of the person with his or her learning context and is assisted through the learner his/herself giving attention to observing what is happening in themselves and in their external environment, intervening in various ways to influence themselves and the context in which they are operating and reflecting-in-action continually to modify their observation and interventions.

\subsection{Taxonomies of Reflective Practice}

During the last twenty years there has been a growing body of literature and practices which, has sought to identify different levels of reflection for the maximising of teacher growth (Day, 1993). As reflective practice denotes a wide spectrum of somewhat differing orientations and procedures, researchers and practitioners hold different conceptions of the taxonomy of the notion, depending on their own theoretical assumptions and practical applications. Some scholars assert that reflective practice develops in a sequential manner, and the different forms of reflection are thus the different levels in a hierarchy. However, some scholars argue that the different forms of reflection are only the different orientations to reflective practice; they are in fact complementary to one another, and should therefore not be placed in an order of priority or importance. In the following sections I will bring together the various viewpoints, in an attempt to understand the main line of thought of the two polarized approaches.

\subsubsection{The 'hierarchy' approach}

Handal (1990), in his Practical Theory, splits the concept of reflective practice into three hierarchical levels, namely, actions (P1); practical and theoretical reasons (P2); and ethical justification (P3). He speculates that given the 'busyness' culture of schools, in most situations teachers spend most of their time planning and acting (constructing practice) at the P1 level, and less on observation and reflection (deconstructing practice) at levels P2 and P3. He concludes that studying critically one's own practice is not yet established.

Hatton and Smith (1995) propose a framework to illustrate the nature of reflection, which indicates a perceived developmental sequence. It recognises that an ideal end-point for fostering reflective approaches is the eventual development of a capacity to undertake reflection-in-action, the most demanding type of reflecting upon one's own practice. The start point is technical rationality, which then moves onto reflection-on-action. They then argue that there are five distinctive forms of reflection, namely, technical, descriptive, dialogic, critical and contextualisation of multiple viewpoints. 


\subsubsection{The 'non-hierarchy' approach}

Schon (1987) distinguishes between two types of reflection: reflection-in-action and reflection-on-action. It is mainatined that reflection-in-action occurs whilst practising, and influences the decisions made and the action taken. Eraut (1994) maintains that due to time factor, reflection-in-action is best seen as a 'metacognitive process' in which there is rapid interpretation of information and decision making in the midst of action. Whereas, reflection-on-action takes place after the event, and although there may still be pressures of time, the interface between thought and action is displaced so there is more scope for trial and experiment.

Eraut, in a critique of Schon's (1983) model of reflective practice, concludes that, "There is insufficient discrimination between the rather different forms of reflection depicted in his many examples; and this overgeneralisation causes confusion and weakens his theoretical interpretations (Eraut, 1994: 145)." He further argues that the concept of 'reflection-in-action' is itself now due for reframing (Eraut, 1995).

Based on specific social science paradigms, and fundamenatal beliefs and values about education, Wellington (1996) puts forward five orientations to reflective practice: the immediate which focuses on the immediate demands and pleasant survival; the technical which focuses on instructional methodologies for maximum efficiency and effectiveness; the deliberative which emphasises personal meaning in an educational context; the dialectic which advocates political liberation; and the transpersonal which centres on universal personal liberation. He stresses that these five orientations are interactive and interdependent, rather than competing views of what is practical, and each orientation contributes to the fully developed educator. Practitioners need to recognise their current level of proficiency and their capacity for growth within each orientation, then they could as a result use reflection as a way to improve their practice.

After going through the two different approaches, I echo with Day's view (1999b) that it is important that teachers engage in different forms of reflection variously during their career lives in accordance with their individual itineraries of professional development, and no single form of reflection is superior than others and teachers must be engaged in all. The different forms of reflection are, therefore, parts of a continuum, instead of different levels in a hierarchy.

\subsection{Facilitating Conditions/Strategies for Reflective Practice}

The encouragement of reflective practice requires more than debriefing or introducing a new topic into the curriculum; it requires finding appropriate ways to build the notions into the processes of teaching and learning (Boud and Knights 1996).

\subsubsection{Strategies / techniques}

A number of strategies have been identified as facilitative to reflection, for instance, the use of learning journals and learning partners (critical friendship), debriefing activities, critical incident analysis, autobiographical work, the creation of concept maps, action research and various forms of computer-based dialogue (Boud, Keogh and Walker 1985; Zeichner 1986; Holly 1989; Rosenthal 1991). These strategies are generally conceptualised as carrying the function of 'turning experience into learning' (Boud, Keogh and Walker 1985) or providing students with the opportunities to process their experience to generate alternative ways of viewing a situation and achieving new appreciations or understandings. Students are encouraged to return to their own experiences in class and outside and focus on what these events mean to them. (Boud and Knights 1996).

Hatton \& Smith (1995) argue that although numerous approaches are claimed to foster reflection, there is little research evidence to clearly show whether they are effective or not. They identify four broad strategies, namely, action research projects, ethnographic and case studies, microteaching and other supervised practicum experiences and structured curriculum tasks. Other more specific techniques include various versions of reading fiction and non-fiction, oral interviews, and writing tasks, such as keeping journals, personal narratives, student metaphors for teaching, or reflective essays drawing on practicum experiences.

They further point out that time is required for reflective capacities to develop, so that essential metacognitive skills can be acquired. It is necessary to adopt a developmental approach in programmes of teacher education. A suitable and relevant knowledge base needs to be identified, one which helps intending teachers first understand then apply concepts of reflection to their own teaching. Student reaction to demands for reflection must be anticipated. Issues relating to the structure and ideology of total programmes need to be addressed, in order that the development of reflection might be encouraged. Assisting teachers to develop reflective skills requires attention. 


\subsubsection{Climate / context}

Boud and Knights (1996) notes that it is useful to create an effective climate for reflection hinging upon learners' active engagement in learning. They suggest the following means that are necessary for establishing a productive climate for reflection:

1. Articulating an educational rationale for the process;

2. Introducing a simple exercise to illustrate reflection;

3. Providing an opportunity for students to clarify their understanding of the idea;

4. Introducing a framework or model to aid thinking about elements of reflection;

5. Modelling a reflective approach in one's own presentation of the idea;

6. Identifying areas of the process that students can make their own;

7. Providing time; and

8. Treating reflection as a normal activity.

\subsubsection{Necessary conditions}

To facilitate reflective thinking, Dewey (1964) asserts that besides knowledge of reflective methods, it is also necessary to develop certain qualities or traits of character such as open-mindedness or sincerity, wholehearted or absorbed interests, responsibility, as well as a habit of thinking in a reflective way.

Argyris and Schon (1974) suggest that theoretical ideas about teaching and learning are likely to stimulate, build and sustain reflection and professional conversations by providing a framework for dialogue.

Day (1993) argues that reflection is a necessary but not sufficient condition for professional development; it must be accompanied by confrontation either by self or others, in the form of active, planned and skilled challenge and support, if development is to occur. He also claims that as reflection is essential in the learning life of the teacher, partnerships and coalitions within collaborative cultures are necessary to support opportunities for the different kinds of reflection so as to foster professional learning cultures. He further argues that besides peer partnerships and networks, collaborative partnerships upon principles of equity with academics of higher education for intellectual, affective and practical support will make relationships between reflective practice, change and improvement explicit (Day, 1999 b).

\subsection{Impediments to Reflective Practice}

According to Jersild (1955), teachers in general are reflective practitioners who strive to develop and grow as persons and professionals. However, in day-to-day professional lives, this notion is not always readily apparent or easily realised. What makes true reflection in action difficult is that life in classrooms is contingent, dynamic, and ever-changing: every moment, every second is situation-specific. Moments of teaching are ongoing incidents that require instant actions. Hatton \& Smith (1995) also remark that reflection is not generally associated with teacher's work, which is seen to be about immediate and pragmatic action.

There are thousands of publications on the topic of reflection in educational contexts variously exploring characterisations, forms, purposes, and rationales for reflective practice, and offering suggestions for how to engage in reflective practice, when, where, and with whom. However, Cole (1997) observes that there exists a theory-practice rift. She further notes that it seems that, no matter how much attention we have paid to exploring the concept, overall we have not helped teachers be reflective practitioners.

Cole's view is supported by Day. The problems in sustaining reflective practice have been well documented in research on the busyness of school work; the pressures caused by increased bureaucracy due to new forms of accountability; the difficulties of self-confrontation which challenges beliefs and practices that have become valued routines and may lead to possibilities of potentially uncomfortable, temporarily disruptive change processes (Day, 1993). In addition to these, cultures in schools which often discourage disclosure, feedback and collaboration act as potential barriers to participation in all forms of reflective practice (Day, 1999b).

Day (1999b) highlights the following factors as impediments to reflection: (1) little time is available; (2) most teachers' learning is incidental, occurring in the classroom; (3) teachers' learning lives are characterised by fragmentation and discontinuty; (4) direct classroom experience seems to be the principle means for learning; and (5) few schools or individual teachers routinely plan for intervention by others into their natural learning lives for the purpose of peer assisted learning. 


\title{
2.6 Criticism of Reflection/Reflective Practice
}

Recent literature emphasising reflective practice spans a broad range of professions, disciplines, methodologies and applications. A lot of claims have been made on the central role that reflection plays in the professional development of teachers. However, I would say most of them are on the intellectual plane only, and basically axiomatic, instead of empirical, by nature. The scene is somewhat murky, according to Day $(1993,1999)$ as to how reflection may lead to change. He remarks that:

\begin{abstract}
"We do not know very much, for example, about how it is that teachers make decisions based upon reflection or how to judge the quality of the decisions in action, how to ensure that the reflective process really can lead to empowerment." (Day, 1993: 90)
\end{abstract}

He further notes that,

"Whether most teachers engage in systematic reflection which contributes to their development and capacity to improve the quality of learning opportunities for students remains an open question." (Day, 1999:1)

Similarly, a number of American researchers identify reflection as being an essential part of learning which itself is under-researched. They put it:

"For all the popularity of reflection as an appropriate stance for professional educators, there is little research evidence that relates reflectivity to other conditions in teachers' professional lives. An examination of the literature reveals a general assumption that reflection in professional behaviour is desirable but very little guidance as to how confidently to determine that reflective behaviour exists." (Copeland, et al: 1991)

To conclude, reflection is a more problematic concept than is generally considered and that there is a need for critical debate about the nature of reflection, its role in learning and its inclusion in university courses. The literature on the subject is growing rapidly, but a lot more systematic work is required before we can really confident that the particular practices currently being adopted are having the influences we desire (Boud and Knights 1996: 32).

\section{The Research Study}

\subsection{Objectives of the Study}

Although there is considerable current interest in reflective practice, the subject has thus far been under-researched, according to a number of researcher-practitioners (Copeland et al 1991; Griffiths \& Tann 1991; Boud \& Knights 1996; Day 1999). The objective of this research study is not to develop knowledge that can be used to theorise or make generalisations for wider applicability, but to contribute to increased understanding of the various viewpoints on reflective practice held by adult educators. According to Elbaz-Luwisch (1997), this search for a knowledge that empowers rather than making possible prediction and control, is a significant reconceptualisation of the purpose of educational research.

Four objectives are set to guide this research study.

1. To investigate adult educators' attitude towards reflective practice;

2. To investigate if there is a disparity between adult educators' attitude and their actual practices;

3. To explore factors that affect adult educators' involvement in reflective practice; and

4. To explore the problems and possibilities.

\subsection{Research Questions}

My survey sought to elicit adult educators' reaction to the following research questions.

Research Question 1

Do adult educators hold positive attitude towards reflective practice?

Research Question 2

How do adult educators perceive/understand reflective practice?

Research Question 3

Do they practise what they believe? 
Research Question 4

What are the problems and possibilities?

\subsection{Methodology and Procedure}

Due to the relatively short time-scale, I had to keep the study within a practicable limit as far as possible. I adopted qualitative research method for this study, which involved individual and focus group interviews with the target group by stratified purposeful sampling.

The research site was an adult education institution in North Cyprus. Approval was obtained from the management prior to the survey. In order to enable triangulation of data sources (Denzin, 1970), two samples were drawn from the senior administrators; three from the assistant administrators; and four from the teaching personnel. The profile of the interviewees is depicted in Appendix 1.

Both the focus group interviews and individual interviews were semi-structured and guided by a framework based on four core questions (Appendix 2). Individual interviews were conducted to six of the respondents. Four out of the six individual interviews were conducted face to face and two over the telephone so as to accommodate the many different time-scales of the respondents. The telephone interviews were done upon the request of the interviewees for the reason that they could not find time to meet the interviewer. A focus group interview was conducted to three of the respondents. The original idea of conducting a focus group interview was to save time and to obtain a wider range of opinions however, it produced an effect far from its original intended purpose.

In order to make the interviews more fruitful, I conducted a pre-interview survey whereby all the interviewees were asked whether they had knowledge about reflective practice and how they learned about it. Only the two senior administrators indicated that they had come across similar terms, like reflection, reflective thinking, before. Consequently, I requested the respondents to read two articles, namely, 'The Nature of Reflection-on-practice' by Ghaye and Ghaye (1999), and 'Reflection: A necessay but not sufficient conditions for professional development' by Day (1993) so as to give them some idea about the subject prior to the interviews.

At the beginning of the interviews, the respondents were fully briefed of the purpose and value of the research study, the promise of anonymity, and the confidentiality of discussion. Considering the psychological effect of taperecording on the interviewees (Bell, 1999) during the interviews, I employed the note-taking method for recording their views.

\subsection{Analysis}

\subsubsection{On the understanding of reflective practice and its significance to educators:}

According to the pre-interview survey, a great majority of the respondents demonstrated no or little knowledge of reflective practice. One senior administrator recalled that he came across a similar term, 'reflection', when he was at seminary [SA1]. Another senior administrator recalled that he dealt with the topic 'reflective thinking' when he was on his doctoral programme [SA2]. The rest of the respondents indicated that they had never had any systematic inquiry into the subject, but they regarded it as a generic term and a common practice shared by all educators who were serious about their work as well as the development of the profession.

Some respondents claimed that reflection was important to personal as well as professional growth.

"I taught in a secondary school before. Now as an adult educator, I have to be well aware of the difference between pedagogy and andragogy. This could only be achieved through constant reflection on my own practice. It's very important for my personal and professional growth" [T4].

The assistant administrators echoed with the teacher's view on professional development.

"There are different levels of reflection, and each of which could contribute to professional development" [AA1]. "Reflection is necessary for the improvement of practice" [AA2]. "It's a longstanding common practice for professionalism" [AA3].

Two of the teachers used reflection as a tool for evaluation.

"I think we engage in reflection every day and it is an on-going exercise for improved practice. I use it as an evaluation 
tool for my teaching performance" [T1].

"Reflective practice is necessary for development, and it is particularly useful for self-evaluation" [T2].

Besides as a means for evaluation, two teachers expressed that reflection should be related to research.

"In my opinion, reflective practice is not just arm-chair meditation; it should be related to action research. It is a systematic, structured, scientific activity hinging upon a strategy and with a well-defined purpose" [T2].

"Reflection is a mirror. Its images develop from other people's comments, both students and colleagues. It could further develop by using research as a means for solving the practical problems in the workplace" [T3].

The senior administrators regarded reflective practice as an important means to manage change and re-orient practice. One of them revealed that reflective practice could challenge routine practice and help us keep abreast with the rapidly changing world.
"I believe reflective practice could help us be conscious of the applicability of pre-set values and assumption, as well as taken-for-granted practices in a rapidly changing world" [SA2].

The other senior administrator held a similar view.

\begin{abstract}
"At a secular level, reflective practice is a critical inquiry into our own practices as adult educators; at the metaphysical level, it is a drive for the improvement of mankind. It not only helps us confront new challenges; but we could also overcome human weaknesses through opening ourselves to critical inquiry. In the field of education, there are many conventional practices. As we move to the knowledge society, we have to response promptly to a multitude of changes, at both micro and macro levels. In fact, success in change is inextricably linked to reflective practice "[SA1].
\end{abstract}

\title{
3.4.2 On the involvement in reflective practice:
}

All the respondents indicated that they engage in different forms of reflection variously in their course of career. They also note that the degree of rigorousness of the various form of reflection is, to large extent, determined by the capacities that they undertake. One teacher revealed that:

"As a teacher, I engage in the descriptive type of reflection nearly after every lesson, and the receptive and interactive types of reflection with my colleagues comes naturally whenever we have sharing about our teaching. Starting from this term, I have been seconded to the Education Department, undertaking a special research project on 'Drama in Education', which aims to promote drama education in North Cyprus. I have to design the curriculum, deliver pilot classes and conduct a survey to collect feedback. This project enables me to move from the classroom to the wider context. It's natural that more critical type of reflection will be involved" [T1].

The assistant administrators expressed a consensus view on the effect of reflection due to capacity:

"We do engage in different forms of reflection. However, we are the middle management and are expected to execute instructions only. We are not at the policy-making level, it seems that no matter how deep we involved in reflection, we won't be able to effect any changes" [AA 1, 2 \& 3].

"Basically, I concern what happen in the classroom more than anything else. So I reflect a lot upon my teaching. The impact of the education reform has done me least; it doesn't affect me too much" [T3].

However, a number of respondents indicated that the recent education reform has led them to engage more in the critical type of reflection.

"As the Government invites responses to the reform agenda regularly, and the senior management demands reformdriven action plans, often we have to reflect critically on ways to improve education and how to lobby the Government in its policy formulation; how we could manage the changes that are advocated; and in what ways we could best partner with the Government" [SA1].

"The education reform has already implemented for one year. It advocates a lot of new concepts in education and 
pedagogic innovations. In the past year, I found myself engaged more in critical inquiry into my own practice in line with what are upheld in the reform proposals" [T4].

A teacher indicated that he has the practice of keeping a learning journal and showed his appreciation to the degree of autonomy and the support rendered by the institute.

"I write diary on my teaching every day. My motto is 'today's self is better than yesterday's, and tomorrow's is better than today's'. I enjoy recording every bit of my reflection in the diary: the students' feedback; self-evaluation; comments from colleagues; learning from various sources, etc. I do engage in various forms of reflection. I appreciate the high degree of autonomy in teaching and the support from the institute" [T2].

A senior administrator claims that reflective thinking is generated by the desire for genuine communication, and levels of reflection are related to career life stages.

"Reflective practice are both means and ends. If we look for genuine communication, it's quite automatic that we will engage in reflection thinking. According to my own experience, levels of reflection are closely linked with practice; different levels of reflection and career life stages are inter-related. " [SA1].

However, another senior administrator put forward an opposing view on whether there is a hierarchy in reflection:

"The different forms of reflection are not in a linear progression. We engage in different forms of reflection, depending on contexts and needs" [SA2].

\subsubsection{On the problems and possibilities}

Nearly all respondents expressed that time is a crucial factor to the involvement in reflection. Some respondents expressed their frustration that:

"I know it very well reflection carries an important impact to the improvement of the quality of education, but I always lack the time to reflect. I have to take up 24 teaching hours a week and my workload is too heavy. I'm glad that I am now seconded to the Education Department, I should have more time to reflect" [T1].

"We are always overloaded by the routines. As we expand our service due to the increasing size of the learners, we have to strive for resources and take note of the budget all the time. Whenever we gather together, we handle those immediate matters first, and reflection in the form of challenge and debate is obviously not the priority task. Time is definitely an impediment and the ever increased team size also makes opportunities for collective reflection difficult" [SA2].

"We are always occupied by a multitude of tasks, and it's difficult to set priority. Time is definitely insufficient for the completion of all the tasks in an effectual way. It seems a matter of course to put reflection aside when there is a more urgent matter to settle. Other competing commitments of life also reduce the opportunities to reflect" [AA2].

Other respondents indicated that besides time, there are other factors affecting the involvement in reflection:

"Whether reflection-on-practice works depends largely on personality maturity and it also links to life stages. I think other factors, such as resource support, opportunities available, and supportive mechanism in place, can also facilitate reflection [T2].

"There should be more dialogues within and between different levels of the staff, so that we could facilitate one another in reflection-on-practice through better communication. We have already institutionalised a number of measures, like the annual Reflection Day/Camp for the administrators and assistant administrators, and regular brain-storming sessions at all levels" [SA1].

A teacher expressed her wish for institutional support for teachers as well:

"I think it'll be great if there's a Teachers' Development Day/Camp. Just an occasion for us to gather together, share our problems and work out solutions. A chance to retreat collectively is important for development and growth" [T3]. 
An assistant administrator who is responsible for organising programmes for the purpose of reflection mentioned the difficulties that she encountered and expressed her view on the issue of whether these activities should be mandatory:

"The contextual factor is important to promote and maintain the spirit of reflective practice. It's also necessary to engage in some sort of research for the practical benefit of learners. I am responsible for organising the annual reflection camps and the sharing sessions on the mutual search for meaning of life, but the response is not very favourable because the participants think that these activities are not immediately useful to them. I am increasingly of the view that reflection must be spontaneous; and it cannot be imposed. We should provide the opportunities, but it should be on a voluntary basis, and it should not be mandatory" [AA1].

A teacher offers the following view, which perhaps serves as an answer to the issue of whether participation in 'officially organised' reflective activities should be voluntary:

"It's important that the Agency supports reflection-on-practice through concrete measures, like organising meaningful activities. I have to admit that I'm not too sensitive to changes in the wider context and I hope the Agency could play an auxiliary role here. If reflection-on-practice could be done in groups, it's more likely to achieve shared vision and promote mutual understanding, which will, as a result, lead to improved practice. However, the themes and tasks of these programmes must be carefully chosen. They must fulfil the needs of the participants, otherwise no significant impact will result" [T1].

A senior administrator holds a similar view:

"We do have a range of opportunities to facilitate our staff to engage in reflection. Depending on life experiences and mindset, some people may need more focused activities, whereas some favour broad-based ones. However, the focus for each activity must be clear and the process more interactive" [SA2].

A number of respondents pointed out the importance of partnership:

"I find it more fruitful if I could have support from my colleagues, and ideally, if we could collaborate during the course of reflection. I think reflective practice works best in a form of collegial partnership, and it should be much better than on individual basis" [T3].

"The presence of critical friends to challenge critically, but in a supportive manner, during the process of reflection is crucial. I wish I could have a mentor. Actually, I am trying to form some sort of informal network among colleagues. As we share a common ground and encounter similar problems, I think we could support one other in a lot of ways" [T4].

"Critical friends can play a facilitating role in reflective practice. As it is a collaborative relationship, we need interpersonal intelligence to maintain it" [SA1].

"Colleagues with shared vision and value are important stimulus and support to reflection" [SA2].

\section{Conclusion}

The findings of this research study indicate that all the respondents, irrespective of their positions held, have a favourable attitude towards reflective practice, despite the fact that most of them have never had any systematic inquiry into the subject. Their interpretations to the term are based on their understanding and knowledge derived from their practices. They all regard reflective practice as an important means for personal and professional growth. They also point out that it could also help us challenge routine practice and keep abreast with the rapidly changing world.

All the respondents have engaged in different forms of reflection variously in their course of career, and a particular form may be more prominent due to capacities. However, some claim that the different forms of reflection are in a hierarchy and related to career life stages, and some think otherwise. Some respondents claim that research is an effective way to facilitate reflection-on-practice.

Although the respondents are eager to engage in reflective practice, sometimes they fail to do so due to various constraints. They regard time as the major impediment to reflection-on-practice. When there are some other tasks/jobs, which are more pressing, they tend to surrender to the competing commitments at work or of life.

There are some conditions necessary for effective reflection-on-practice to take place, for example, personality 
maturity, life stages, resource support, opportunities available and supportive mechanism in place, etc. It is generally agreed that institutional support is essential to reflective practice, and meaningful activities with a clear focus and relevancy for the purpose of reflecting collectively, be it voluntary or mandatory, should be institutionalised. The availability of critical friendship and partnership, based on a collaborative relationship, is considered to be of central importance to reflective practice, whereby practitioners could have critical inquiries by themselves as well as others in a supportive manner. It is apparent that reflective practice is a desirable professional behaviour among adult educators, however, this behaviour does not automatically lead to improved practice. This study demonstrates that adult educators need support and guidance in developing appropriate strategies for reflective practice and transform it into a catalyst for professional growth.

\section{References}

Argyris, C. and Schön, D.A. (1974) Theory in Practices: Increasing Professional Effectiveness, New York, Jossey-Bass.

Britzman, D.P. (1990) Practice makes practice: A critical study of learning to teach. Albany: State University of New York Press.

Carr, W. And Kemmis, S. (1986) Becoming Critical: Education, Knowledge and Action Research, London, Falmer Press.

Clark, C.M. and Yinger, R.J. (1979) Three studies of teacher planning, (Research Series No.55) East Lansing: Michigan State University, Institude for Research on Teaching.

Cochran-Smith, M. and Lytle, S.L. (1996) 'Communities for teacher research: Fringe or forefront?', in McLaughlin, M.W. and Oberman, I. (eds) Teacher Learning: New Policies, New Practices, New York, Teachers College Press, pp.92-114.

Cohen, L., Manion, L., and Morrison, K. (2000) Research Methods in Education. London: Routledge Falmer.

Copeland, W.D., Birmingham,C., De La Cruz, E. and Recht, B. (1991) 'The reflective practitioner in teaching: Toward a research agenda', Paper presented at Annual Conference of the American Educational Research Association, April 3-7, 1991, Chicago.

Day, C. (1993) Reflection: a necessary but not sufficient condition for professional development. British Educational Research Journal, Vol.19, No.1, pp.83-93.

Day, C. (1995) "Qualitative research, professional development and the role of teacher educators: fitness for purpose." British Educational Research Journal, Vol.21, No.3, pp.357-369.

Day, C. (1999) Developing Teachers, The Challenges of Lifelong Learning. UK: Falmer Press.

Day.C.W. (1999) Professional Development and reflective Practice: Purposes and Partnerships. Curriculum Studies, Vol.7, No.2

Dewey, J. (1910) How We Think (Boston, D.C. Health).

Dowsett, G. (1986) Interaction in the semi-structured interview in M. Emery (Ed.), Qualitative Research. Canberra: Australian Association of Adult Education.

Elbaz-Luwisch, F. (1997) Narrative Research: Political Issues and Implications. Teaching and Teacher Education, Vol.13, No.1, pp.7583. Pergamon Publishers.

Elbaz, F. (1988) Critical reflection on teaching:insights from Freire, Journal of Education for Teaching, 14, pp.171-181.

Eraut, M.E. (1994) Developing Professional Knowledge and Competence, London: Falmer Press.

Fenstermacher, G. (1990) 'Some moral considerations on teaching as a profession', in Goodland, J., Soder, R. And Sirotnik, K. (eds) The Moral Dimensions of Teaching, San Francisco, Jossey-Bass, pp.130-51.

Goodson, I. (1994) Studying the Teacher's Life and Work. In Bennett, N. (Ed) Teaching and Teacher Education, Vol.10, No.1, pp.29-37. Pergamon Press Ltd.

Goodson, I.F. (1992) Studying teachers' lives. London:Routledge and New York: Teachers College Press.

Hargreaves, A. (1996) Revisiting Voice. Educational Researcher, Vol.25. No.1, pp.12-19.

Jackson, P.W., Boostrom, R.E. and Hansen, D.T. (1993) The Moral Life of Schools, San Francisco, Jossey-Bass.

Johnston, S. (1994) 'Is action research a "Natural" Process for Teachers?, Educational Action Research Journal, 2, 1, pp.39-48.

Kvale, S. (1996) Interviews. London: Sage Publications.

Louden, W. (1991) Understanding teaching:Continuity and change in teachers' knowledge. New York: Teachers College Press.

Mc Laughlin, M.W. (1993) 'What matters most in teachers' work place context?' in Little, J.W. and Mc Laughlin, M.W (eds) Teachers' Work: Individuals, Colleagues and Contexts, New York, Teachers College Press.

Nias, J. (1987) Seeing A new: teachers' theories of action (Victoria, Australia, Deakin University Press).

Osterman, K. And Kottkamp, R. (1993) Reflective Practice for Eduactors. London, Corwin Press.

Reynolds, M. And Salters, M. (1998) The Reflective Teacher and the Teacher Training Agency. Journal of Further and Higher Education, Vol.22, No.2, pp.193-199.

Schön, D.A.(1983) The Reflective Practitioner: How Professionals Think in Action, New York, Basic Books.

Schön, D.A. (1987) Educating the Reflective Practitioner: Toward a New Design for Teaching and Learning in the Professions, New York, Basic Books.

Tuckman, B.W. (1972) Conducting Educational Research. New York: Harcourt Brace Jovanovich.

Wellington, B. And Austin, P. (1996) Orientations to reflective practice. Educational Research, Vol.38, No.3, pp.307-316. 